\title{
Schwannoma of Brachial Plexus
}

\author{
Ameet Kumar • Saeed Akhtar
}

Received: 21 May 2009 / Accepted: 16 July 2009 / Published online: 19 November 2010

(C) Association of Surgeons of India 2010

\begin{abstract}
Brachial plexus tumours are a rare entity. Schwannomas are benign nerve sheath tumours and only about $5 \%$ arise from the brachial plexus. Due to its rarity and complex anatomical location they can pose a formidable challenge to surgeons. We present a case of a young patient who presented with an axillary swelling three months after a lymph node biopsy from the same axilla, which turned out to be a Schwannoma arising for the medial cord of the brachial plexus.
\end{abstract}

Keywords Brachial plexus tumours · Schwannoma .

Axillary swelling

\section{Case Summary}

A 17 year old male presented with swelling and pain in his left axilla of 15 days' duration. On examination, he had a $5 \times 4 \mathrm{~cm}$ firm swelling in the left axilla. There was no neurological deficit in the upper limb.

An FNAC was hemorrhagic. A CT scan of chest revealed a $7.6 \times 4.3 \mathrm{~cm}$ mass in left axilla posterior to pectoralis major and anterior axillary artery which showed heterogeneous enhancement and suggestive of a lymph node mass or a neurogenic tumour (Fig. 1).

A. Kumar $(\bowtie)$

Department of Surgery, Air Force Hospital Rowriah, Jorhat,

Assam 785005, India

e-mail: mythurs@hotmail.com

S. Akhtar

Regency Hospital Ltd.,

Kanpur 208005, India

e-mail: akhtarsaeed@hotmail.com
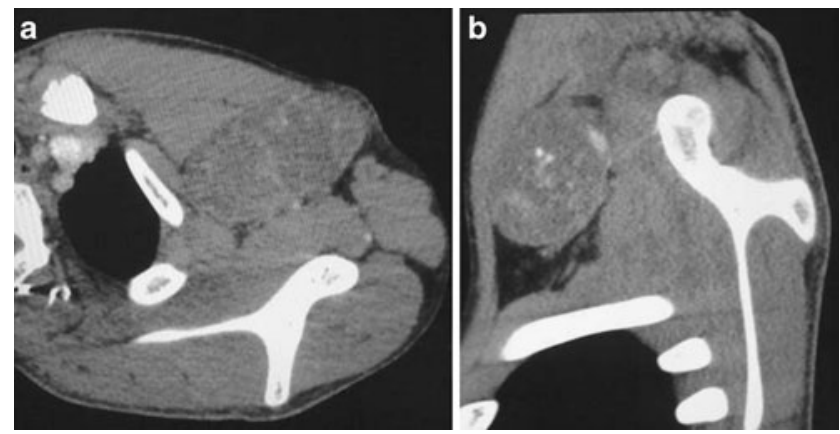

Fig. 1 a. Contrast enhanced CT scan showing the isodense lesion in axilla with minimal enhancement. b. Sagittal reformatted image showing the tumour

During surgery for excision through an axillary approach, a $6 \times 4 \mathrm{~cm}$ firm mass arising from the medial cord was found (Fig. 2). The tumour was enucleated avoiding any damage to cord. In the post operative period, the patient

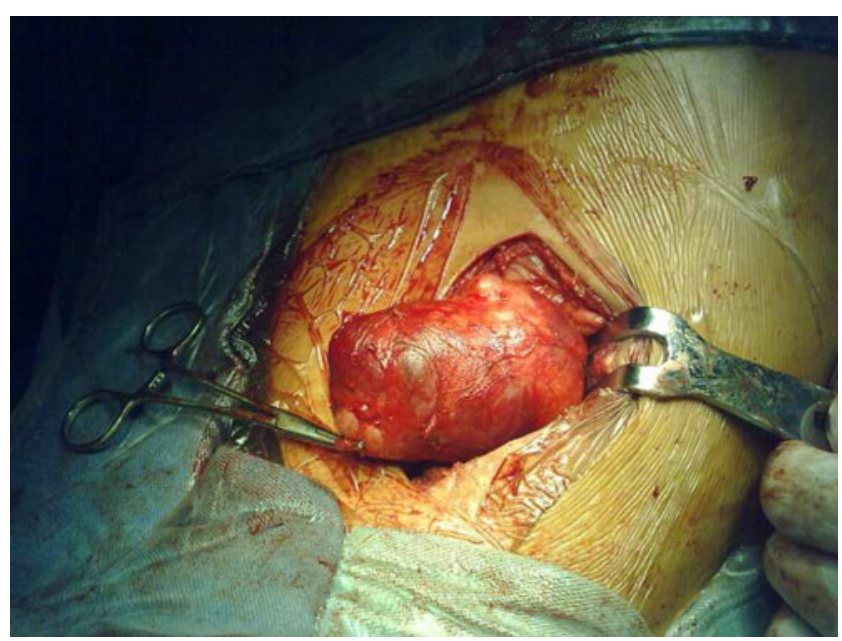

Fig. 2 Per-operative photograph of the tumour 
complained of loss of sensation over index finger and thumb. The histopathology of the tumour was consistent with Schwannoma.

\section{Discussion}

Brachial plexus tumours are rare comprising of only $5 \%$ of all tumours of upper limb [1]. The two most common brachial plexus region tumors are the Schwannomas and the Neurofibromas, both of which are benign and arise from the nerve sheath [2]. The most frequent site is in the head and neck, which comprises $25 \%$ of all Schwannomas, and only about $5 \%$ of Schwannomas present as brachial plexus tumours $[3,4]$. Due to their rarity and complex anatomical location they form a formidable diagnostic and therapeutic challenge to surgeons [1].

Schwannomas are indolent tumors but may present with symptoms secondary to nerve compression. Grossly these tumours are oval or plexiform and may be pink, tan, yellow or gray [3]. Histologically, the terms Antoni type A and type B are used to describe varying growth patterns in Schwannomas.

Imaging studies are valuable in the pre-operative diagnosis. On CT, most Schwannomas are iso-dense relative to brain parenchyma. Calcification or areas of hemorrhage are rare and the enhancement pattern is typically homogeneous [5]. On MRI Schwannomas are iso-intense to hypo-intense on T1weighted MRI and enhance with gadolinium [6].

Surgery is indicated for tumors that cause neurological dysfunction or pain or for any rapidly growing tumors with a suspicion of malignancy, and complete resection of these tumors results in cure [3].

\section{References}

1. Donner TR, Voorhies RM, Kline DG (1994) Neural sheath tumours of major nerves. J Neurosurg 81:362-373

2. Ganju A, Roosen N, Kline DG et al (2001) Outcomes in a consecutive series of 111 surgically treated plexal tumors: a review of the experience at the Louisiana State University Health Sciences Center. J Neurosurg 95:51-60

3. Huang JH, Samadani U, Zager EL (2003) Brachial plexus region tumors: a review of their history, classification, surgical management, and outcomes. Neurosurg Q 13:151-161

4. Ahn KM, Lee HK, Lee KD, Yu TH (2002) A case of neurilemmoma of the brachial plexus. J Korean Otolaryngol 45:733-735

5. Chung SY, Kim DI, Lee BH et al (1998) Facial nerve schwannomas: CT and MR findings. Yonsei Med J 39(2):148-153

6. Bartolome A, Gonzalez-Alenda J, Bartolome MJ et al (1998) Study of the brachial plexus by magnetic resonance. Rev Neurol 26:983988 